\title{
Medical uses of Carthamus tinctorius $L$. (Safflower): a comprehensive review from Traditional Medicine to Modern Medicine
}

\author{
Elahe Delshad ${ }^{1}$, Mahdi Yousefi ${ }^{2}$, Payam Sasannezhad ${ }^{3}$, Hasan Rakhshandeh ${ }^{4}$, Zahra Ayati ${ }^{5}$
}

${ }^{1}$ PhD Student, Department of Persian Medicine, School of Persian and Complementary Medicine, Mashhad University of Medical Sciences, Mashhad, Iran

${ }^{2} \mathrm{PhD}$ of Health Economics, Assistant Professor, Department of Persian Medicine, School of Persian and Complementary Medicine, Mashhad University of Medical Sciences, Mashhad, Iran

${ }^{3}$ Neurologist, Assistant Professor, Department of Neurology, School of Medicine, Mashhad University of Medical Sciences, Mashhad, Iran

${ }^{4}$ Pharm.D, Assistant Professor, Pharmacological Research Center of Medicinal Plants, Mashhad University of Medical Sciences, Mashhad, Iran

${ }^{5} \mathrm{PhD}$ Student, Department of Traditional Pharmacy, School of Pharmacy, Mashhad University of Medical Sciences, Mashhad, Iran

\section{Type of article: Review}

\begin{abstract}
Background: Carthamus tinctorius L., known as Kafesheh (Persian) and safflower (English) is vastly utilized in Traditional Medicine for various medical conditions, namely dysmenorrhea, amenorrhea, postpartum abdominal pain and mass, trauma and pain of joints. It is largely used for flavoring and coloring purposes among the local population. Recent reviews have addressed the uses of the plant in various ethnomedical systems.

Objective: This review was an update to provide a summary on the botanical features, uses in Iranian folklore and modern medical applications of safflower.

Methods: A main database containing important early published texts written in Persian, together with electronic papers was established on ethnopharmacology and modern pharmacology of C. tinctorius. Literature review was performed on the years from 1937 to 2016 in Web of Science, PubMed, Scientific Information Database, Google Scholar, and Scopus for the terms "Kafesheh", "safflower", "Carthamus tinctorius", and so forth.

Results: Safflower is an indispensable element of Iranian folklore medicine, with a variety of applications due to laxative effects. Also, it was recommended as treatment for rheumatism and paralysis, vitiligo and black spots, psoriasis, mouth ulcers, phlegm humor, poisoning, numb limbs, melancholy humor, and the like. According to the modern pharmacological and clinical examinations, safflower provides promising opportunities for the amelioration of myocardial ischemia, coagulation, thrombosis, inflammation, toxicity, cancer, and so forth. However, there have been some reports on its undesirable effects on male and female fertility. Most of these beneficial therapeutic effects were correlated to hydroxysafflor yellow A.

Conclusion: More attention should be drawn to the lack of a thorough phytochemical investigation. The potential implications of safflower based on Persian traditional medicine, such as the treatment of rheumatism and paralysis, vitiligo and black spots, psoriasis, mouth ulcers, phlegm humor, poisoning, numb limbs, and melancholy humor warrant further consideration.
\end{abstract}

Keywords: Carthamus tinctorius, Persian traditional medicine, Modern medicine

\section{Introduction}

Carthamus tinctorius L., widely accepted as Safflower or false saffron, belongs to the Compositae or Asteraceae family. This thistle-like species typically thrives in an arid climate, namely Southern Asia, China, India, Iran, and

\section{Corresponding author:}

Zahra Ayati, Department of Traditional Pharmacy, School of Pharmacy, Mashhad University of Medical Sciences, Mashhad, Iran. Tel: +98.9155576029, Email: ayatiz941@gmail.com

Received: September 29, 2017, Accepted: March 30, 2018, Published: April 2018

iThenticate screening: March 31, 2018, English editing: April 08, 2018, Quality control: April 12, 2018

This article has been reviewed / commented by five experts

(C) 2018 The Authors. This is an open access article under the terms of the Creative Commons Attribution-NonCommercialNoDerivs License, which permits use and distribution in any medium, provided the original work is properly cited, the use is non-commercial and no modifications or adaptations are made. 
Egypt (1). It is found with six species in Iran (2-4). It was introduced into western countries, such as Italy, France, Spain, and the United States during the 5th to the 14th centuries. The vernacular name of this plant in Iran is "Golrang", "Kajireh", and "Kafesheh", which has been vastly cultivated for its flower petals containing the red and orange pigments. The other well-known names for safflower are "Zaffer", "Fake Saffron", and Dyer's Saffron" (5). It has been shown that the scavenging activities of safflower petals can produce a range of colors from orange to white with various intensities (6). Therefore, this plant is used for numerous culinary and textile purposes. With the advent of synthetic aniline dyes, it has been mainly grown as an oilseed and birdseed that has some applications in medicinal fields (7). More to the point, its oil has high nutritional value and consists of $70 \%$ polyunsaturated fatty acid (i.e., linoleic acid), 10\% monounsaturated oleic acid, and mere amounts of stearic acid $(8,9)$. Safflower remarkably shows purgative, analgesic and antipyretic characteristics, and is useful in patients with poisoning (10). Of note, this plant species is clinically associated with considerable outcomes for the treatment or management of menstrual cramps, post-partum hemorrhage, whooping cough and chronic bronchitis, rheumatism, and sciatica (11). The flowers of C. tinctorius are traditionally applied for cardiovascular, cerebrovascular, and gynecological complications. In this regard, Zhou et al. shed light on the phytotherapeutic potency of the water extract of $C$. tinctorius for cardiovascular diseases (12). As for other biological activities linked to its water extract, it is regarded as an anticoagulant, vasodilating, antihypertensive, antioxidative, neuroprotective, immunosuppressive, anticancer agent with inhibitory impacts on the synthesis of melanin (12). Furthermore, it was indicated that safflower is effective for other ailments involving the neurotropic, cardiotropic, hemopoietic, and diaphoretic systems (13). Concerning the phytochemistry of this plant, pertained studies have pinpointed a number of active constituents, such as flavonoids, phenylethanoid glycosides, coumarins, fatty acids, and steroids identified from various parts of the plant (12). Currently, a body of pharmaceutical studies has focused on its ethno-pharmaceutical applications in terms of antioxidation, anti-inflammation, and anti-epilepsy (14-16). The existing safflower literature provides a deep scope on the plant varieties, main constituents, and pharmaceutical uses chiefly based on Chinese and Indian traditional medicine. To extend the view towards future implications of this plant species for medicinal and clinical purposes, this study was intended to update current knowledge on its other traditional uses, clinical properties, and pharmacological potentials of $C$. tinctorius according to modern medicine and various ethnomedical systems, including traditional medicine among the Iranian population. Medicinal activities of the plant are highlighted considering in vitro, in vivo, and clinical evidence.

\section{Material and Methods}

This narrative review was conducted to address different applications of safflower from the views of Persian traditional medicine and modern medicine. Nine major published texts, including Makhzan-ol-Advieh, Gharabadine-Kabir, al-Havi, Identification of Medicinal and Aromatic Plants of Iran, al-Mansuri Fi At-Tibb, Qanun, Zakhire Kharazmshahi, Riaz al-Advieh and Maaref giahi (Plant Knowledge), as well as five electronic databases, such as Web of Science, PubMed, Scientific Information Database (SID), Google Scholar, and Scopus during the years from 1937 to 2016 were searched and reviewed for morphological features, traditional uses, and medical reports on C. tinctorius. The vernacular as well as scientific names, such as "Kafesheh", "safflower", and "Carthamus tinctorius", "Golrang", "Kazireh", "Kajireh", "Osfor", "Qortom", "Khasq", "Kavisheh", "Saffron color", "Ihriz", and "Khoube'e" were used for collecting pertained literature across the World Wide Web and texts. The plant names have been checked with the Plant List (17).

\section{Results and discussion}

\subsection{Botany}

As for the morphological features, safflower is described as a bushy, herbaceous annual or winter annual plant with upright and cylindrical stems and alternate, ovate or ovate-lanceolate leaves, on which there might be spines (18). Accordingly, two varieties are distinguished based on the presence or absence of spines, namely spiny and spineless. This botanical characteristic has shown to influence the amount of oil content (19). The whole plant's branches (i.e. of primary, secondary, and tertiary types) terminate into tubular flower heads known as capitula (21). These flowers in bright yellow, orange or red are enclosed by spiny bracts (20). It has many thin horizontal lateral roots along with a tap root, which can grow at depths of over two meters to use nutrients and groundwater storages under arid climates. Nevertheless, this plant species is cultivated under greenhouse or rain-fed conditions $(19,21)$.

\subsection{Traditional and Folk Uses}

From a historical perspective, safflower seeds and packets, and garlands of florets were widely found in the presence of mummies across ancient Egypt (22). Moreover, safflower is consumed raw in wide regions of Iran (23). Safflower dye was used in Italian, French and British cuisine as a flavoring and a coloring. Florets were diversely 
applied as a dye, coloring, flavoring, rouge, potion and unguent. Safflower dyes were especially of utmost importance for the carpet-weaving industries in Eastern Europe, the Middle East and the Indian subcontinent (24). This special application is obviously identifiable in the second half of its binomial name; those plants with the word "tinctorius" or its derivatives typically have any background use as a dye (25). In Thailand, aqueous extract of safflower flowers has largely been used as hair color promoter (26). In Indian traditional medicine, safflower is typically used for scabies, arthritis, and mastalgia. Also, this plant species finds a usual application for the treatment of amenorrhea, gastric tumors, as well as wounds, with internal or external origins among Chinese folklore. Of note, skin patches, baldness, phlegm, and colic can be treated by using safflower based on Iranian traditional medicine (5). The traditional use of safflower among Persian folklore is presented in Table 1. C. tinctorius has been utilized in Persian folk medicine for the treatment of diabetes, phlegmatic fever, melancholia, and dropsy (6, 27, 28). Additionally, various plants from Compositae family are traditionally used as an abortion-promoting agent. The water extract of safflower is applied in painful menstruation for sedation, as a laxative for constipation as well as an anti-inflammatory remedy in traditional medicine (29). The dried floret of $C$. tinctorius named Carthami flos has found great popularity due to its wide use in treating coronary heart disease, angina pectoris, gynecologic disease, stroke, and hypertension (30).

Table 1. Different applications of safflower in the traditional Persian textbooks

\begin{tabular}{|l|l|l|}
\hline Ref. no & Plant part & Properties \\
\hline 31 & Flower, seeds & Laxative effects \\
& Seed oil & Rheumatism and paralysis \\
\hline 32 & - & Easy uptake by target tissue \\
& - & Tissue contraction \\
Treatment of vitiligo and black spots \\
& - & Treatment of Psoriasis \\
& - & Treatment of mouth ulcers \\
& - & Pain relief \\
& - & Phlegm humor (Balgham) reduction \\
& Fruit, leaves & Anti-poison (scorpion) \\
& - & Treatment of numb limbs \\
\hline 33 & Saxative \\
\hline 34 & Seeds & Laxative \\
& Seeds & Melancholy humor (soda) reduction \\
& Seeds & Semen improvement \\
\hline
\end{tabular}

\subsection{Medical Implications Based on Modern Medicine}

Safflower has been used in some regions of Asia and Africa as a remedy acting like laxatives and antidotes to poison, and a medicinal oil in order to enhance sweating and cure fevers (22). It was reported that all parts of the plant have been traditionally employed to increase libido in Pakistan and India (8). Removing bitter principles, the Institute of Botany affiliated to the Chinese Academy of Sciences in Beijing has processed a new sweet-smelling product well rich in amino acids, minerals and vitamins B1, B2, B12, C and E (22). There has been numerous evidence in support of the use of safflower medicines for menstrual problems, cardiovascular complications as well as pain and swelling in trauma cases $(18,20)$. The applications of safflower for different medical conditions based on modern medicine are summarized in Table 2.

\subsubsection{Musculoskeletal system}

It was indicated that the pharmacology of safflower contains the excitation of smooth muscles. A dose-dependent raise in contraction characteristics (frequency and amplitude) of uterine tissue in animals such as dogs, rats, cavies, and mice continued over 4 hours. When it came to exert excitation effects on intestinal muscle in the same species, the response persisted for a short period. The bronchi smooth muscle of the cavy was also impacted (35). Moreover, contraction influences of safflower have also been reported on vessel networks of toad and of dog kidney, yet with a decrease in kidney volume. However, safflower extracts cause a long-term drop in blood pressure in dogs, cats, and rats with hypertension (36). In dogs, it was shown that injections of safflower can retard the injury to the heart muscle following an infarction (37). Interestingly, in folk Chinese medicine, safflower was suggested for sciatica, thorax rheumatism, and rheumatoid arthritis (38-40). Its seeds appeared highly influential in clinical treatments of osteoporosis and rheumatism (41); this claim is investigated through an animal trial on anti-bone resorption features of safflower seed. The results highlighted that this plant and its combination with TGF- $\beta 1$ can diminish the amounts of cyclooxygenase-2 mRNA, prostaglandin E2, as well as phosphorylation of peptide substrates, whereby bone 
resorption is inhibited. However this potential is dose-dependent, safflower can be used as a natural Src family kinase inhibitor (41).

\subsubsection{Cardiovascular system}

The flower extract was demonstrated to enhance peripheral blood flow, inhibit platelet aggregation, and produce beating of myocardial cell sheets (42). This extract can afford to inhibit or reverse the adrenaline-induced decline in capillary blood flow of rats (43). Another experimental analysis on the extract of safflower showed that higher concentration of $C$. tinctorius around $13.5 \%$ demonstrated the most significant clot lytic activity without any hemolysis (44). Low concentrations of safflower decoction resulted in an increase in the amplitude and systolic volume of the heartbeat in dogs. A 14-day intervention using safflower yellow diminished total cholesterol and augmented HDL cholesterol in rabbits without any given impacts on beta-lipoproteins, triglycerides or liver function (45). Furthermore, Carthamins yellow isolated from safflower with an oral dose of 100 and $200 \mathrm{mg} / \mathrm{kg}$ is shown to reduce the blood fluidity in rats with blood stasis, which is of utmost importance in hemorheological disorders (46). Since safflower can afford to invigorate the blood circulation, it has been chiefly used for cardiovascular complications. It was exhibited that $83 \%$ of subjects with coronary disease who received a six-week treatment based on safflower, presented a reduced blood cholesterol level (38). Heart arrhythmia and hypertension were decreased though a period a TID safflower treatment for four weeks (38). A combination of safflower and other herbs in the form of a nasal drip accelerated blood flow in the medial cranial artery (46). The administration of safflower extract at Feng fu, Yamen, Feng chi, along with other acupuncture points every three days improved blood flow in the coronary artery (38). High-quality edible oil is extracted from brilliant safflower, which finds rich in polyunsaturated fatty acids of utmost importance for managing the cholesterol level in blood. It is nutritionally akin to olive oil due to the high amounts of linoleic or oleic acid. The monounsaturated fatty acid for instance, oleic acid, is helpful in the attempt to reduce low-density lipoprotein (LDL; bad cholesterol) while having no undesirable impacts on highdensity lipoprotein (HDL; good cholesterol) in blood. The oil is demonstrated non-allergenic and appropriate in administering medicines by injection (47). Safflower oil with high amounts of unsaturated fatty acids can decrease the plasma level of cholesterol (48). It was reported that injectable safflower can afford to treat 40 subjects presenting coronary disease and angina pectoris, with a total effective rate of $90 \%$ (49). In a rat model, safflower reduced platelet aggregation and blood coagulation (50). Likewise, Zhengliang et al. observed that safflower yellow at $220 \mathrm{mg} / \mathrm{mL}$ had notable potential to inhibit the aggregation of rabbit platelets and prevent rat thrombosis $(51,52)$. Moreover, safflower yellow caused a strong and long-lasting analgesic influence. In animal experiments on mice, the foot-lifting response as a result of formaldehyde, the histamine-mediated enhancement in capillary blood flow, and granulation induced by cotton-ball irritation were all prevented in the presence of safflower (51). The therapeutic impact of hydroxysafflor yellow A, a main active compound in Carthami flos, was examined on rats inflected with focal cerebral ischemia by using an initial concentration of $3 \mathrm{mg} / \mathrm{kg}$. The results revealed that this ingredient can suppress thrombosis formation, inhibit platelet aggregation, and moderate PGI2/TXA2 in rats (53, 54). Two quinochalcone agents in florets of safflower have been reported to cause anti-inflammatory effects; ginkgolide B (IC50 $5.45 \times 10-6 \mathrm{~mol} / \mathrm{L}$ ), saffloquinoside A (IC50 10-5 mol/L) significantly decrease the production of $\beta$-glucuronidase from polymorphonuclear neutrophils induced by the platelet-activating factor (55). Safflower can dilate arteries, diminish hypertension and enhance blood flow and, then improve tissue oxygenation. It causes thrombus formation and dissolves thrombi in the long run (24). A safflower-based treatment in a case of cerebral thrombosis led to an enhanced and lowered blood pressure which is evident in the majority of patients $(38,56)$. Furthermore, herbal decoctions that contained safflower were associated with promising outcomes for the treatment of cerebral embolism (57). In a meta-analysis study, the treatment of patients with acute ischemic stroke was investigated by injecting red safflower. It was presented that this plant can enhance neurologic functional deficits with 1.19 the relative risk $99 \%$ credible region, 7.14 the number of treatments required, and -0.62 the weight mean deviation (58). The probable mechanism behind such impact regards a decrease in the plasma ratio of IL-6/IL-10 along with an increase in the concentration of superoxide dismutase, chloramphenicol acetyltransferase, and malondialdehyde, which can suppress the lipid peroxidation (59). In another comparative study, the superior effectiveness of safflower yellow and hydroxysafflor yellow A for acute ischemic stroke has been demonstrated as opposed to ginkgo leaf and dipyridamole $(60,61)$. 
http://www.ephysician.ir

Table 2. Summary of studies on the medical contribution of safflower to different organs

\begin{tabular}{|c|c|c|c|c|}
\hline $\begin{array}{l}\text { Ref. } \\
\text { no. }\end{array}$ & Study & Design & Intervention & Major findings \\
\hline 42 & $\begin{array}{l}\text { Antioxidant and } \\
\text { neuroprotective activities of } \\
\text { Mogami-benibana (safflower, } \\
\text { Carthamus tinctorius Linne) }\end{array}$ & $\begin{array}{l}\text { In vitro }(\mathrm{C} 6 \\
\text { glia cell) } \\
\text { Rats }\end{array}$ & $\begin{array}{l}\text { Water extracts of } \\
\text { Mogami-benibana } \\
\text { petals (bud, early } \\
\text { stage, full } \\
\text { blooming and } \\
\text { ending stage) }\end{array}$ & $\begin{array}{l}\text {-inhibited glutamate-induced C6 glia cell } \\
\text { death } \\
\text {-significantly decreased the formation of } \\
\text { malondialdehyde in mouse cerebrum, and } \\
\text { inhibited the increase in thiobarbituric acid } \\
\text { reactive substances and 8-hydroxy-2'- } \\
\text { deoxyguanosine ( } 8 \text {-OHdG) in the cerebral } \\
\text { cortex of rats subjected to an injection of } \\
\mathrm{FeCl}(3) \text { solution into the sensory motor cortex }\end{array}$ \\
\hline 62 & $\begin{array}{l}\text { Inhibitory effect of alkane- } 6,8- \\
\text { diols, the components of } \\
\text { safflower, on tumor promotion } \\
\text { by } 12-O-\text { tetradecanoylphorbol- } \\
13 \text {-acetate in two-stage } \\
\text { carcinogenesis in mouse skin }\end{array}$ & Mice & $\begin{array}{l}\text { The mixture of } \\
\text { erythro-alkane- } \\
6,8 \text {-diols from the } \\
\text { flowers }\end{array}$ & $\begin{array}{l}\text {-markedly suppressed the promoting effect of } \\
\text { TPA on skin tumor formation in mice } \\
\text { following initiation with 7,12- } \\
\text { dimethylbenz[a]anthracene }\end{array}$ \\
\hline 63 & $\begin{array}{l}\text { Carthamus tinctorius flower } \\
\text { extract prevents } \mathrm{H} 2 \mathrm{O} 2 \text {-induced } \\
\text { dysfunction and oxidative } \\
\text { damage in osteoblastic MC3T3- } \\
\text { E1 cells }\end{array}$ & $\begin{array}{l}\text { In vitro } \\
\text { (osteoblastic } \\
\text { MC3T3-E1 } \\
\text { cells) }\end{array}$ & Flower extract & $\begin{array}{l}\text {-the } \mathrm{H}(2) \mathrm{O}(2) \text {-induced alterations were } \\
\text { prevented } \\
\text {-the increased production of protein carbonyl } \\
\text { and malondialdehyde was also reduced } \\
\text { - C. tinctorius flower can act as a biological } \\
\text { antioxidant } \\
\text { - protect osteoblasts from oxidative stress- } \\
\text { induced toxicity }\end{array}$ \\
\hline 44 & $\begin{array}{l}\text { Assessment of clot lytic effect } \\
\text { of Carthamus tinctorius } \\
\text { (Golrang) }\end{array}$ & $\begin{array}{l}\text { In vitro (blood } \\
\text { samples from } \\
\text { healthy } \\
\text { individuals) }\end{array}$ & Flower extract & $\begin{array}{l}\text {-the significant percentage of clot lysis was } \\
\text { observed when higher doses of Carthamus } \\
\text { tinctorius extracts were used (about 13.5\%) } \\
\text { - no hemolysis was observed in all } \\
\text { concentrations }\end{array}$ \\
\hline 36 & $\begin{array}{l}\text { Hypotensive effects of } \\
\text { safflower yellow in } \\
\text { spontaneously hypertensive rats } \\
\text { and influence on plasma renin } \\
\text { activity and angiotensin II level }\end{array}$ & Rats & Safflower yellow & $\begin{array}{l}\text { - lowered the blood pressure } \\
\text { - the plasma renin activity and angiotensin II } \\
\text { level diminished }\end{array}$ \\
\hline 46 & $\begin{array}{l}\text { Effect of the carthamins yellow } \\
\text { from Carthamus tinctorius } L \text {. } \\
\text { on hemorheological disorders } \\
\text { of blood stasis in rats }\end{array}$ & Rats & $\begin{array}{l}\text { Carthamins } \\
\text { yellow isolated } \\
\text { from Carthamus } \\
\text { tinctorius L. }\end{array}$ & $\begin{array}{l}\text { - significantly decreased the whole blood } \\
\text { viscosity, plasma viscosity, and erythrocyte } \\
\text { aggregation index } \\
\text { - Hematocrit and platelet aggregation were } \\
\text { reduced, while prothrombin time was delayed } \\
\text { with increasing doses }\end{array}$ \\
\hline 64 & $\begin{array}{l}\text { Effects of Carthamus tinctorius } \\
L . \text { on the ovarian } \\
\text { histomorphology and the } \\
\text { female reproductive hormones } \\
\text { in mice }\end{array}$ & Mice & $\begin{array}{l}\text { C. tinctorius } \\
\text { extract }\end{array}$ & $\begin{array}{l}\text { - reduced the number of ovarian follicles but } \\
\text { number of atretic follicles showed an increase } \\
\text { - The number and size of the corpora lutea } \\
\text { were not affected } \\
\text { - the thickness of the tunica albuginea was } \\
\text { increased but the relative and absolute weights } \\
\text { of the ovaries decreased significantly } \\
\text { - the blood levels of the FSH and estrogen } \\
\text { were decreased }\end{array}$ \\
\hline
\end{tabular}




\subsubsection{Reproductive organs}

In a comparative study, safflower treatment raised uterus weight in ovariectomized mice and seminal vesicle weight in castrated mice as compared with sex hormones (65). Demonstrated as a fertility moderator in traditional medicine, Louei Monfared and Salati in an animal setting, administered intraperitoneally C. tinctorius extract for 49 consecutive days, revealing that the number of ovarian follicles declined as the number of atretic follicles increased. Moreover, the thickness of the tunica albuginea was on the rise, yet the relative and absolute weights of the ovaries diminished notably. The FSH and estrogen were decreased in those mice which received different doses of $C$. tinctorius extract. Thus, C. tinctorius extract has vehemently adverse impacts on the ovarian histomorphology and female reproductive hormones (64). A concentration of $0.2-2 \mathrm{mg} / \mathrm{kg} /$ day of safflower extract during the early days of the gestation period is associated with histological changes in the nervous system of mouse embryos (66). Moreover, it was indicated that $C$. tinctorius flower extract can disturb the development of mice embryos. Accordingly, women are recommended to evade using Carthamus flowers during pregnancy (67). Accordingly in Iranian traditional medicine, the maximum allowable amount of safflower seed and flower is $20-40 \mathrm{gr}$, and 3 gr per day, respectively (5). The consumption of safflower is also associated with undesirable consequences on male fertility, which is supported by an animal trial where aqueous extract of safflower was used to study its toxic effects on mouse testis when injected at $40 \mathrm{mg} / \mathrm{kg}$ for 25 consecutive days (23).

\subsubsection{Others}

Safflower has an improving effect on hair growth in mice, which is probably correlated to hydroxysafflor yellow A. This major compound may affect the mRNA expressions of vascular endothelial growth factor and keratinocyte growth factor while suppressing the mRNA expression of transforming growth factor- $\beta 1$ (TGF- $\beta 1$ ) in keratinocytes and dermal papilla cells (68). Similarly, in another in vitro and in vivo study, the effectiveness of safflower for enhancing hair growth was corroborated; ethanol extract of $C$. tinctorius was seen to have the inhibitoriest influence on $5 \alpha$-reductase activity among 17 Thai plants (69). Considerable rates of recovery were observed in cases suffering from alopecia when treated with hair-restoring preparations based on safflower (70). The flower extract was found to increase antibacterial activity, decrease depression symptoms, relieve inflammation, and retard progression of skin tumors (42). The two last properties are related to the presence of sterols, and erytro-alkane-6,8-diols (62). Carthamus tinctorius $L$. was reported to present moderate antiplasmodial activity. Its aerial part has $42.3 \%$ suppression and over $100 \mu \mathrm{g} / \mathrm{mL}$ cytotoxicity (71). In an in vitro investigation on ethyl acetate and methanol extracts of safflower, the therapeutic potential was confirmed for skin infections and wounds due to the antimicrobial characteristics against $C$. neoformans, antimalarial activity against $P$. falciparum D6 and $P$. falciparum W2, and antileishmanial effects against $L$. donovani (72). The antioxidant properties have only been observed in petal extract of this plant $(42,63)$. Moreover, safflower has free radical scavenging activity, which is related to the presence and content of carthamin $(63,73)$. Furthermore, it is reported that Carthami flowers may increase the frequency of mutation $(74,75)$. Zhou Cai combined both western and Chinese medicine including safflower to investigate its effectiveness on hemiplegia (76). More to the point, safflower in addition to other herbs has been successfully used to treat respiratory conditions, namely pertussis and chronic bronchitis (38). A spray throat containing safflower in water had no serious consequences yet showed beneficial results for about half of 100 patients with acute laryngitis, pharyngitis, and other throat complex conditions (77). A regimen of 50 to $120 \mathrm{mg}$ doses of safflower florets showed effective clinical outcome in $80 \%$ of patients with chronic gastritis and atrophic gastritis (78). Safflower has the therapeutic potential to treat chronic nephritis (38). Safflower eye drops were highly effective especially in pediatric myopia (38).

\section{Conclusions}

This study was an attempt to provide a comprehensive overview on the morphological characteristics, and the therapeutic as well as non-therapeutic potential of safflower with a view towards its traditional and folk uses in different parts of the world, mainly Iran. This plant species has beneficial effects on medical conditions concerning cardiovascular system, musculoskeletal organ, digestive system, and the like. A great number of animal and clinical studies has scrutinized such potentials, which are addressed in this study and can be considered as promising alternatives, if not replacement, for a peculiar medical condition. However, there is still an essential need for further phytochemical analyses and clinical trials on its essential oil or its different extracts. As an example, its antimicrobial as well as antioxidant effects of safflower not only can be widely used as a food protective agent but also may inhibit or retard the progression of certain diseases, namely vitiligo and black spots, psoriasis, and mouth ulcers. Moreover, some concentrations of safflower show effective outcomes in myocardial ischemia, coagulation, and thrombosis. Despite recent evidence indicating the adverse effects of safflower on the reproductive organs, it would cause semen improvement according to Persian traditional medicine, which necessitates further investigations. 


\section{Acknowledgments:}

This study is part of a $\mathrm{PhD}$ thesis and the authors hereby express their gratitude toward the authorities of Research Deputy in Mashhad University of Medical Sciences.

\section{Conflict of Interest:}

There is no conflict of interest to be declared.

Authors' contributions:

All authors contributed to this project and article equally. All authors read and approved the final manuscript.

\section{References:}

1) Shirwaikar A, Khan S. Medicinal plants for the management of post menopausal osteoporosis: A review. Open Bone J. 2010; 2: 1-13. doi: 10.2174/1876525401002010001.

2) Zhao G, Zheng XW, Gai Y, Chu WJ, Qin GW, Guo LH. Safflower extracts functionally regulate monoamine transporters. Journal of Ethnopharmacology. 2009; 124(1): 116-24. doi: 10.1016/j.jep.2009.04.002.

3) Duke JA, Bogenschutz M, duCellier J, Duke P. Hand book of Medicinal herb. 2 ed. London: RC Press; 2002.

4) Mozaffarian V. A dictionary of Iranian Plant Names. Tehran: Farhang Moaser; 1996.

5) Imami A, Taleb A, Khalili H. PDR for Herbal Medicines. 1 ed. Tehran: Andisheh-Avar; 2010.

6) Asgary S, Rahimi P, Mahzouni P, Madani H. Antidiabetic effect of hydroalcoholic extract of Carthamus tinctorius L. in alloxan-induced diabetic rats. J Res Med Sci. 2012; 17(4): 386-92. PMID: 23267403.

7) Bae CS, Park CH, Cho HJ, Han HJ, Kang SS, Choi SH, et al. Therapeutic effects of safflower (Carthamus tinctorius L.) Seed powder on osteoporosis. Appl Microsc. 2002; 32(3): 285-90.

8) Knowles PF. Centers of plant diversity and conservation of crop germplasm: safflower. Econ Bot. 1969; 23: 324-9. doi: 10.1007/BF02860678.

9) Kumar SP, Kumari BDR. Factors affecting on somatic embryogenesis of safflower (Carthamus tinctorius L) at morphological and biochemical levels. World J Agric Sci. 2011; 7: 197-205.

10) Asgarpanah J, Kazemivash N. Phytochemistry, pharmacology and medicinal properties of Carthamus tinctorius L. Chinese journal of integrative medicine. 2013; 19(2): 153-9. doi: 10.1007/s11655-013-1354-5.

11) Wang G, Li Y. Clinical application of safflower (Carthamus tinctorius). Zhejiang Tradit Chin Med Sci J. 1985; 1: 42-3.

12) Zhou FR, Zhao MB, Tu PF. Simultaneous determination of four nucleosides in Carthamus tinctorius L. and Safflower injection using highperformance liquid chromatography. J Chin Pharm Sci. 2009; 18: 326-30.

13) Punjanon T, Arpornsuwan T, Klinkusoom N. The pharmacological properties of safflower (Carthamus tinctorius L). Bull Health Sci Technol. 2004; 7: 51-63.

14) Jun MS, Ha YM, Kim HS, Jang HJ, Kim YM, Lee YS, et al. Anti-inflammatory action of methanol extract of Carthamus tinctorius involves in heme oxygenase-1 induction. Journal of ethnopharmacology. 2011; 133(2): 524-30. doi: 10.1016/j.jep.2010.10.029.

15) Kasahara Y, Kumaki K, Sato T, Katagiri S. Pharmacological studies on flower petals of Carthamus tinctorius central actions and anti-inflammation. Shoyakugaku Zasshi. 1989; 43: 331-8.

16) Kruawan K, Kangsadalampai K. Antioxidant activity, phenolic compound contents and antimutagenic activity of some water extract of herbs. Thai J Pharm Sci. 2006; 30: 28-35.

17) The Plant List. 2013. Available from: http://www.theplantlist.org.

18) Zhou X, Tang L, Xu Y, Zhou G, Wang Z. Towards a better understanding of medicinal uses of Carthamus tinctorius L. in traditional Chinese medicine: A phytochemical and pharmacological review. Journal of Ethnopharmacology. 2014; 151(1): 27-43. doi: 10.1016/j.jep.2013.10.050.

19) Gautam S, Bhagyawant SS, Srivastava N. Detailed Study On Therapeutic Properties, Uses And Pharmacological Applications Of Safflower (Carthamus Tinctorius L.). Int J Ayurveda Pharm Res. 2015; 2(3): 5-16.

20) Singh V, Nimbkar N. Safflower (Carthamus tinctorius L.). Genetic resources, chromosome engineering, and crop improvement. Boca Raton: CRC press; 2006.

21) Emongor V. Safflower (Carthamus tinctorius L.) the underutilized and neglected crop: A review. Asian J Plant Sci. 2010; 9(6): 299-306. doi: 10.3923/ajps.2010.299.306.

22) Weiss EA. Castor, Sesame and Safflower. London: Leonard Hill; 1971. 
23) Mohamadpour M, Khorsandi L, Mirhoseini M. Toxic effect of Carthamus Tinctorius L. (Safflower) Extract in the Mouse Testis. 13th Royan Congress on Reproductive Biomedicine and 7th Royan Nursing and Midwifery Seminar. Tehran: Int J Fertil Steril; 2012.

24) Dajue L, Mündel HH. Safflower, Carthamus Tinctorius L. Italy: International Plant Genetic Resources Institute; 1996.

25) Guarrera PM. Household dyeing plants and traditional uses in some areas of Italy. J Ethnobiol Ethnomed. 2006; 2(1): 9. doi: 10.1186/1746-4269-2-9.

26) Boonyaprapas N, Chokchaijareonporn O. SamoonPrai Maipeunban (Herbal plants, in Thai). Thailand: Faculty of Pharmacy, Mahidol University; 1996.

27) Aghili Khorasani SMH. Makhzan al-Adwiyyah. Tehran: Tehran University of Medical Sciences; 2011.

28) Muhammad ibn Zakariya Razi. Al-Haavi. 1 ed. Beirut: Dar Ihyaal-Turath al-Arabi; 2001.

29) Zargari A. Medicinal Plants. Tehran: University of Tehran Press; 1992.

30) Tu Y, Xue Y, Guo D, Sun L, Guo M. Carthami flos: a review of its ethnopharmacology, pharmacology and clinical applications. Rev Bras Farmacogn. 2015; 25(5): 553-66. doi: 10.1016/j.bjp.2015.06.001.

31) Razi M. Al-Mansuri Fi At-Tibb. Beirut: Darolkotob Alelmiyeh; 2000.

32) Ibn Sina H. Qanun [A. Sharafkandi, trans]. Kashan: Morsal; 2007.

33) Jorjani E. Zakhireh Kharazmshahi. Qom: Ehya Tebe Tabii Institute; 2012.

34) Uosefi Heravi U. Riaz al-Advieh. 1st ed. Tehran: Institute of Meical History, Islamic Medicine and Complementary Medicine.

35) Shixi S. Studies on pharmacology of safflower and saffron crocus. J Chinese Med Sci. 1955; 5: $443-8$.

36) Liu F, Yang XZ, Li FG, Hu J, Cheng RF. Hypotensive effects of safflower yellow in spontaneously hypertensive rats and influence on plasma renin activity and angiotensin II level. Acta Pharmaceutica Sinica. 1992; 27(10): 785-7. PMID: 1293928.

37) Bingzhang W, Minggang Y, Lei P, Zhanjiu Y. The effects of safflower (Carthamus tinctorius) liquor on ischemic degree of cardiac muscle in different infarct regions of experimental myocardial infarction dog. Acta Pharm Sinica. 1978; 14(8): 474-8.

38) Guimiao W, Yili L. Clinical application of safflower (Carthamus tinctorius). Zhejiang Tradit Chin Med Sci J. 1985; 1: 42-3.

39) Yue W, Luqiu W. A clinical observation on the effect of rheumatic prescription for treatment of rheumatoid arthritis of 50 cases. J Jiangsu Tradit Chin Med. 1990; 11(2): 1-3.

40) Yukun $Z$. The treatment of thorax rheumatism of 800 cases with milkvetchpeach-safflower, etc. decoction. Liaoning Tradit Chin Med Sci J. 1988; 12(9): 19-20.

41) Yuk TH, Kang JH, Lee SR, Yuk SW, Lee KG, Song BY, et al. Inhibitory Effect of Carthamus tinctorius L. Seed Extracts on Bone Resorption Mediated by Tyrosine Kinase, COX-2 (cyclooxygenase) and PG (prostaglandin) E2. Am J Chin Med. 2002; 30(01): 95-108. doi: 10.1142/S0192415X02000119.

42) Hiramatsu M, Takahashi T, Komatsu M, Kido T, Kasahara Y. Antioxidant and neuroprotective activities of Mogami-benibana (safflower, Carthamus tinctorius Linne). Neurochemical research. 2009; 34(4): 795-805. doi: 10.1007/s11064-008-9884-5.

43) Ming Q, Chunmei L, Heqi L, Wenfu L. Effects of some herbs on microcirculation of blood of rat's mesentery. J Chin Tradit Med. 1984; 25(12): 65-7.

44) Yousefi M, Rakhshandeh H, Delshad E, Mahjoub F. Assessemt of clot lytic effect of Carthamus tinctorious (Golrang). Avicenna J Phytomed. 2015; 5: 78.

45) Wenxuan Q, Yunxia Z, Daowu W, Yanying Z, Jianying Y. Effects of safflower yellow pigment on the blood fat and liver function of rabbits. J Lanzhou Coll Med Sci. 1987; 3: 57-60.

46) Li HX, Han SY, Wang XW, Ma X, Zhang K, Wang L, et al. Effect of the carthamins yellow from Carthamus tinctorius L. on hemorheological disorders of blood stasis in rats. Food and chemical toxicology. 2009; 47(8): 1797-802. doi: 10.1016/j.fct.2009.04.026.

47) Smith JR. Safflower Illinois: AOCS Press; 1996. doi: 10.1201/9781439832080.

48) Der Marderosian A. The Review of Natural Products. Missouri: Facts and Comparisons; 2001.

49) Li HM. Clinical effect of Honghua injection on coronary disease and angina pectoris. China J Guang Ming Chin Med. 2012; 27: 83-4.

50) Chengzhu L, Shichun Y, Fengdi Z, Diequn Y. Effects of safflower on blood coagulation function of big rat. Tradit Chin Med. 1983; 14(7): 27-8.

51) Zhengliang H, Qiming G, Zhumei C. Studies on Pharmacology of the yellow pigment of safflower (Carthamus tinctorius L.). Traditi Chin Med. 1984; 15(8): 12-4. 
52) Zhengliang H, Zhumei C, Yuan R. Studies on the resistant effect of safflower yellow pigment on blood coagulation. Tradit Chin Med. 1987; 18(4): 22-5.

53) Zhu H, Wang Z, Ma C, Tian J, Fu F, Li C, et al. Neuroprotective effects of hydroxysafflor yellow A: in vivo and in vitro studies. Planta medica. 2003; 69(5): 429-33. doi: 10.1055/s-2003-39714.

54) Zhu HB, Zhang L, Wang ZH, Tian JW, Fu FH, Liu K, et al. Therapeutic effects of hydroxysafflor yellow A on focal cerebral ischemic injury in rats and its primary mechanisms. Journal of Asian natural products research. 2005; 7(4): 607-13. doi: 10.1080/10286020310001625120.

55) Jiang JS, He J, Feng ZM, Zhang PC. Two new quinochalcones from the florets of Carthamus tinctorius. Organic letters. 2010; 12(6): 1196-9. doi: 10.1021/o1902971w.

56) Damao Y. Application of Xiao Shuan Decoction for treatment on cerebral thrombosis of 68 cases. J Zhejiang Tradit Chin Med. 1987; 22(10): 441.

57) Zuolin Z. The curative effects of Tao-Hong-Si-Wu Decoction for treatment on cerebral embolism of 32 cases. Correspond Tradit Chin Med. 1992; 11(3): 44-5.

58) Ma LH, Li DM, Li KJ. Clinical effect study on ischemic stroke in acute period treated with red flower injection. J Zhejiang Chin Med Univ. 2012; 36: 633-5.

59) Luo CZ, Gao ZQ, Jiang JY, Yang XY, Tang JP, Luo Y. Effects of safflor injection on serum IL-6 and IL10 level of young patients with mild acute cerebral infarction. J Chongqing Med Univ. 2014; 29: 463-5.

60) Xiao X, Hu WJ. Clinical effect of HSYA injection on acute ischemic apoplexy. Med J West China. 2011; 33: 932-6.

61) Xing YL, Tu Q, Xiao QF, Jiao Y. Clinical effect of safflower yellow injection on ischemic apoplexy. Chin Hosp Pharm J. 2008; 28: 1493-5.

62) Yasukawa K, Akihisa T, Kasahara Y, Kaminaga T, Kanno H, Kumaki K, et al. Inhibitory effect of alkane6,8-diols, the components of safflower, on tumor promotion by 12-O-tetradecanoylphorbol-13-acetate in two-stage carcinogenesis in mouse skin. Oncology. 1996; 53(2): 133-6. doi: 10.1159/000227549.

63) Choi EM, Kim GH, Lee YS. Carthamus tinctorius flower extract prevents $\mathrm{H} 2 \mathrm{O} 2$-induced dysfunction and oxidative damage in osteoblastic MC3T3-E1 cells. Phytotherapy research. 2010; 24(7): 1037-41. doi: $10.1002 /$ ptr.3070.

64) Louei Monfared A, Salati AP. Effects of Carthamus tinctorius L. on the ovarian histomorphology and the female reproductive hormones in mice. Avicenna J Phytomed. 2013; 3(2): 171-7. PMID: 25050271, PMCID: PMC4075700.

65) Hanqing J, Meilin C, Shuren M. Observation of the effect of safflower as sex hormone. J Jiamusi Coll Med Sci. 1980; 2: 18-20.

66) Nobakht M, Fattahi M, Hoormand M, Milanian I, Rahbar N, Mahmoudian M. A study on the teratogenic and cytotoxic effects of safflower extract. Journal of ethnopharmacology. 2000; 73(3): 453-9. doi: 10.1016/S0378-8741(00)00324-X. PMID: 11090999.

67) Bahmanpour S, Javidnia K, Arandi H. Weight and crown-rump length reduction, gross malformation and pregnancy outcome in Carthamus tinctorius L-treated mice. Arch Iran Med. 2003; 6(2): 117-20.

68) Junlatat J, Sripanidkulchai B. Hair growth-promoting effect of Carthamus tinctorius floret extract. Phytotherapy research. 2014; 28(7): 1030-6. doi: 10.1002/ptr.5100.

69) Kumar N, Rungseevijitprapa W, Narkkhong NA, Suttajit M, Chaiyasut C. 5alpha-reductase inhibition and hair growth promotion of some Thai plants traditionally used for hair treatment. Journal of ethnopharmacology. 2012; 139(3): 765-71. doi: 10.1016/j.jep.2011.12.010.

70) Shengdong C. Observations on the curative effects of hair-generated agent for treatment on Alopecia areata of 123 cases. Henan Tradit Chin Med Sci. 1990; 10(3): 23-4.

71) Esmaeili S, Ghiaee A, Naghibi F, Mosaddegh M. Antiplasmodial Activity and Cytotoxicity of Plants Used in Traditional Medicine of Iran for the Treatment of Fever. Iranian journal of pharmaceutical research. 2015; 14(Suppl): 103-7. PMID: 26185511, PMCID: PMC4499432.

72) Turgumbayeva AA, Ustenova GO, Stabayeva GC, Ross SA. Phytochemical Screening and Biological Activities of the Camel Thorn (Alhagi kirghisorum) and Safflower Flowers (Carthamus tinctorius L.) Grown in Kazakhstan. American-Eurasian J Agric Environ Sci. 2014; 14(12): 1487-91. doi: 10.5829/idosi.aejaes.2014.14.12.12483.

73) Han SY, Li HX, Bai CC, Wang L, Tu PF. Component analysis and free radical-scavenging potential of Panax notoginseng and Carthamus tinctorius extracts. Chemistry \& biodiversity. 2010; 7(2): 383-91. doi: $10.1002 / \mathrm{cbdv} .200800313$. 
74) Morimoto I, Watanabe F, Osawa T, Okitsu T, Kada T. Mutagenicity screening of crude drugs with Bacillus subtilis rec-assay and Salmonella/microsome reversion assay. Mutation research. 1982; 97(2): 81-102. doi: 10.1016/0165-1161(82)90007-3. PMID: 6804865.

75) Yin XJ, Liu DX, Wang HC, Zhou Y. A study on the mutagenicity of 102 raw pharmaceuticals used in Chinese traditional medicine. Mutat res. 1991; 260(1): 73-82. doi: 10.1016/0165-1218(91)90082-W. PMID: 2027343.

76) Zhoucai L. The treatment on hemiplegia of 288 cases by traditional Chinese and western medicine combination. Shanxi Tradit Chin Med Sci. 1991; 12(10): 444.

77) Shengyun W. Sanhua atomizing agent used for treatment of 100 cases of acute throat diseases. J Heilongjiang Tradit Chin Med. 1985; 6: $23-4$.

78) Lian'en W. Yi Qi Huo Xue Prescription used for treatment of gastritis. J Jiangsu Tradit Chin Med. 1992; 13(1): 35-7. 